\title{
Organic-Inorganic Hybrid Films Fabricated from Cellulose Fibers and Imogolite Nanotubes
}

\author{
Linlin $\mathrm{Li}^{1}$, Wei Ma² , Akihiko Takada ${ }^{3}$, Nobuhisa Takayama ${ }^{1}$, Atsushi Takahara*1,2,3 \\ ${ }^{1}$ Graduate School of Engineering, Kyushu University, 744 Motooka, Nishi-ku, Fukuoka 819-0395, Japan. \\ ${ }_{2}^{2}$ International Institute for Carbon-Neutral Energy Research (WPI-I2CNER), Kyushu University, 744 \\ Motooka, Nishi-ku, Fukuoka 819-0395, Japan \\ ${ }^{3}$ Institute for Materials Chemistry and Engineering, Kyushu University, 744 Motooka, Nishi-ku, Fukuoka 819- \\ 0395, Japan
}

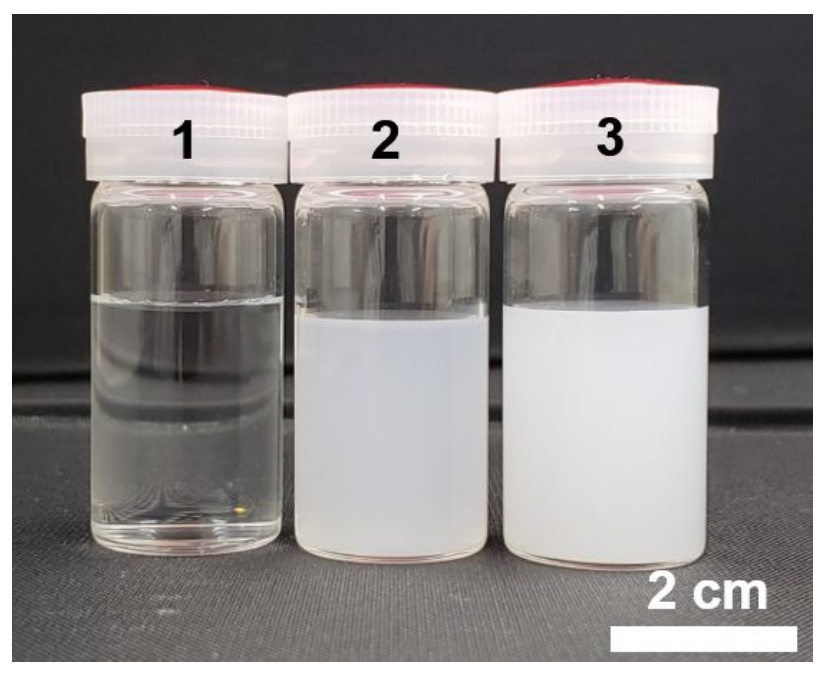

Figure S1 Photographs of (1) $0.3 \mathrm{wt} \%$ imogolite solution, (2) CFs90/Imo10 hybrid solution, and (3) $0.2 \mathrm{wt} \%$ CFs solution. 


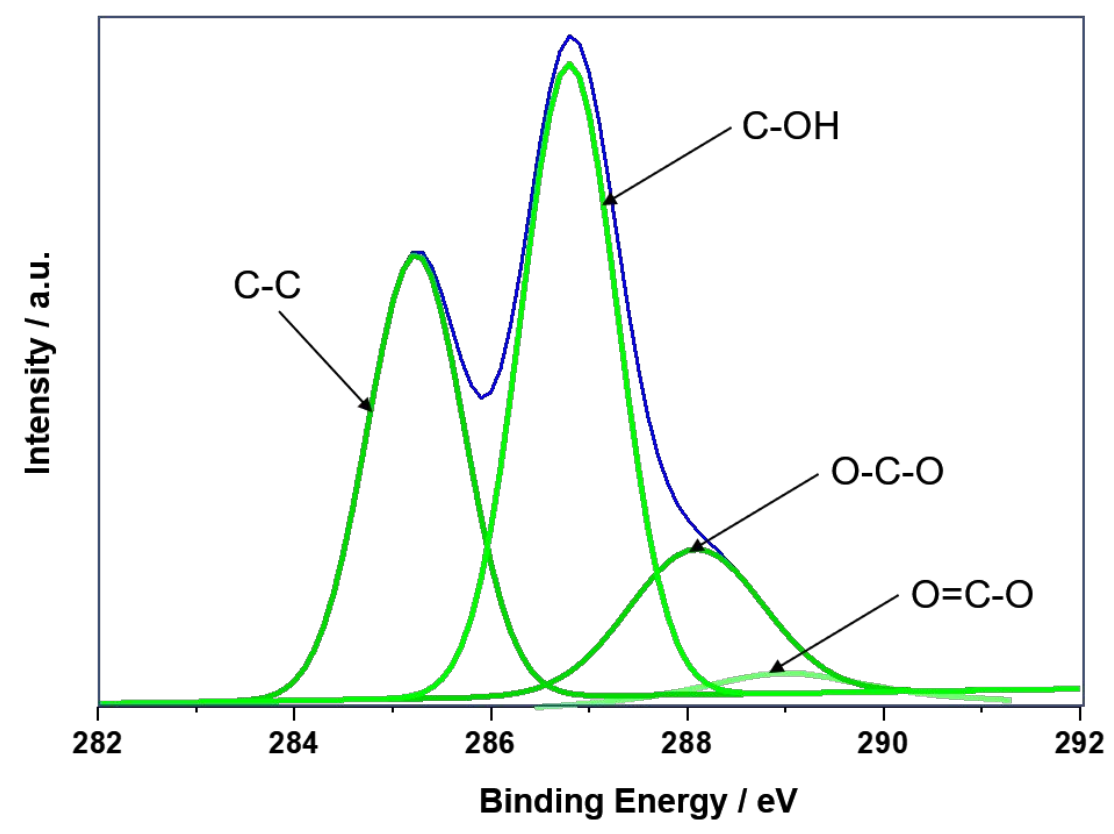

Figure S2 C1s spectra of neat CFs.
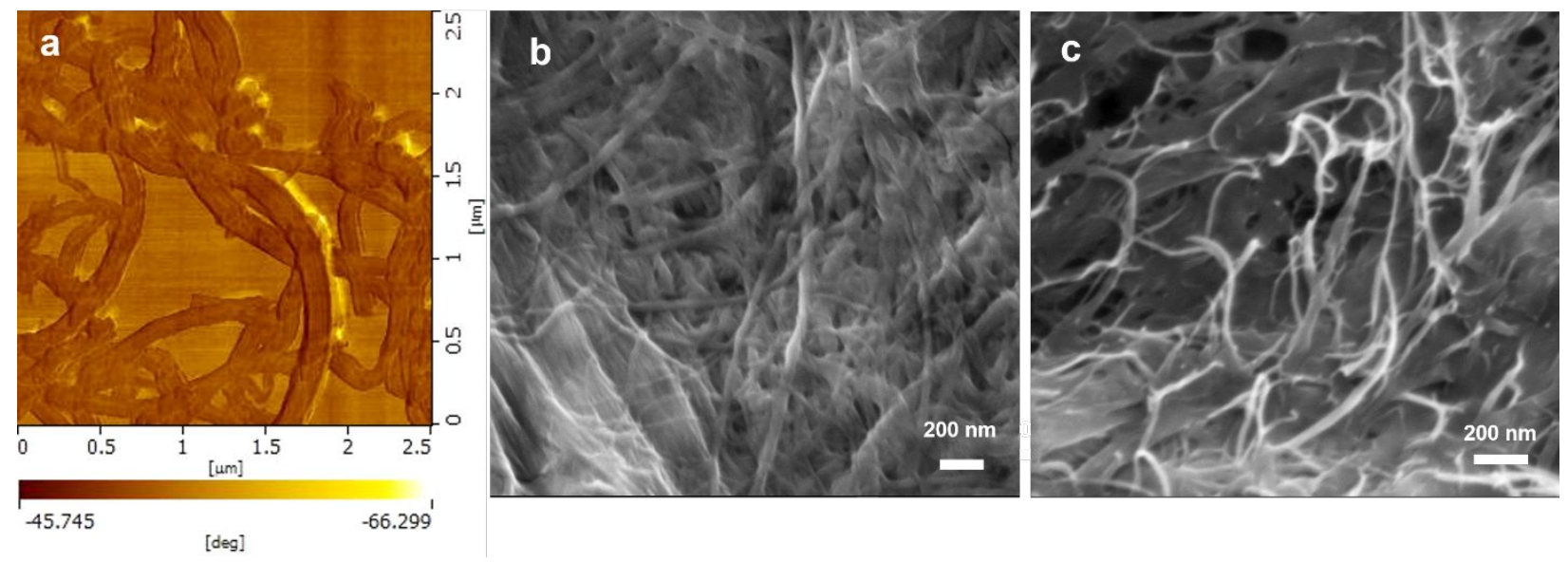

Figure S3 (a) The AFM phase image of neat CFs and SEM images of the surface of (b) neat CFs and (c) CFs90/Imo10 hybrid film. 
a
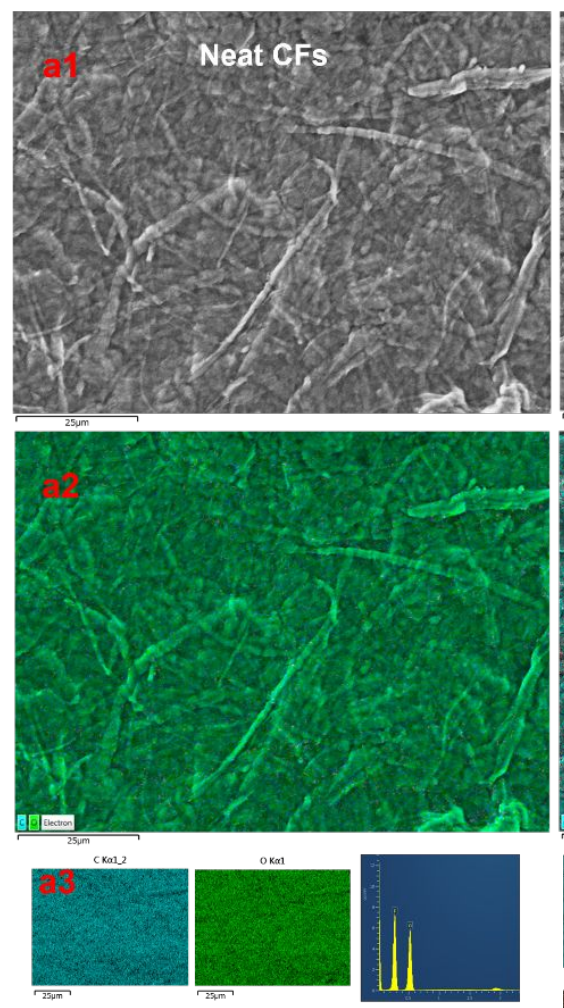

b
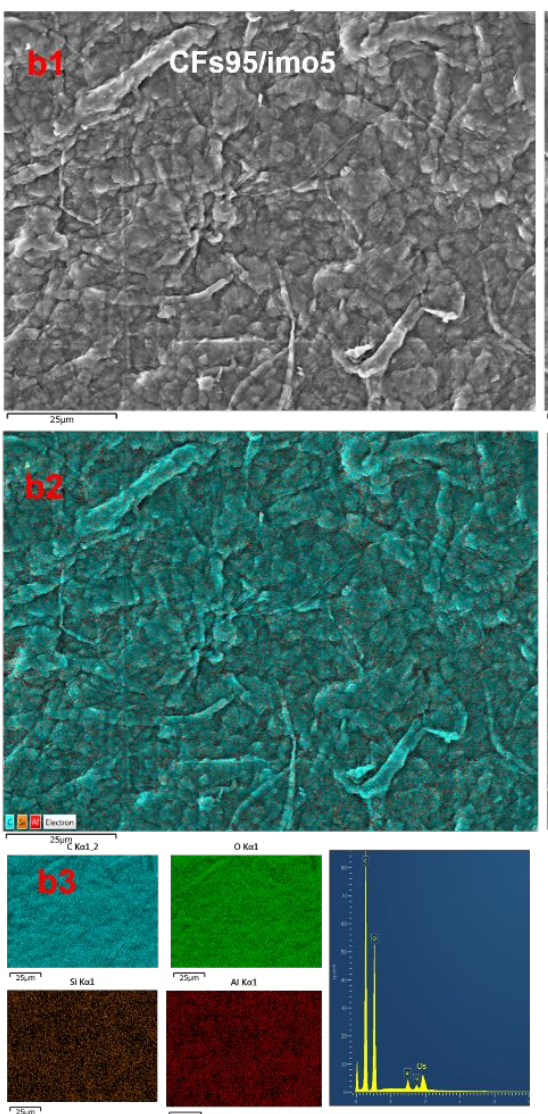

C
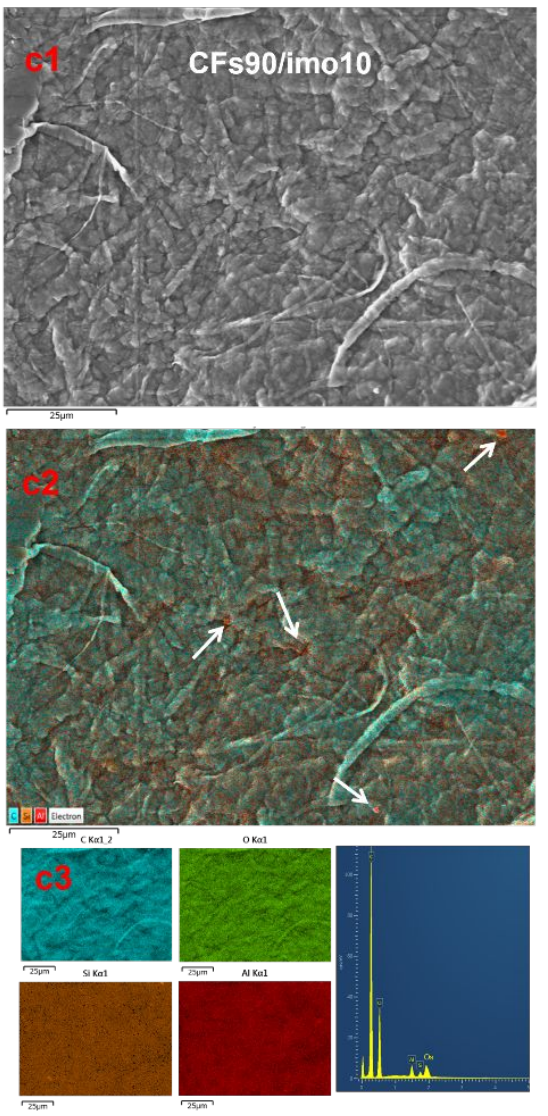

Figure S4 SEM and EDS elemental mapping and spectrum (carbon (light blue), oxygen (light green), silicon (light orange) and aluminum (red)) of neat CFs (a) CFs95/Imo5 (b) and CFs90/Imo10 (c).
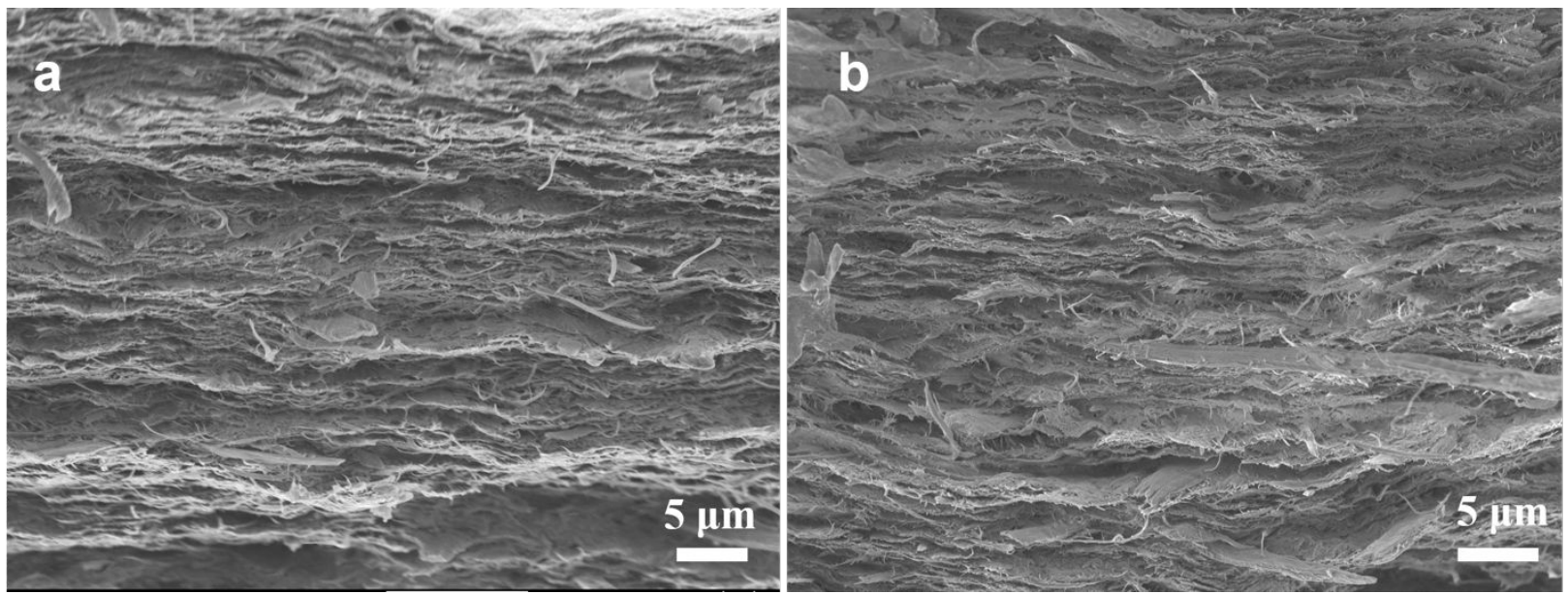

Figure S5 SEM images of cross-section before tensile test of (a) neat CFs film and (b) CFs90/Imo10 hybrid film. 


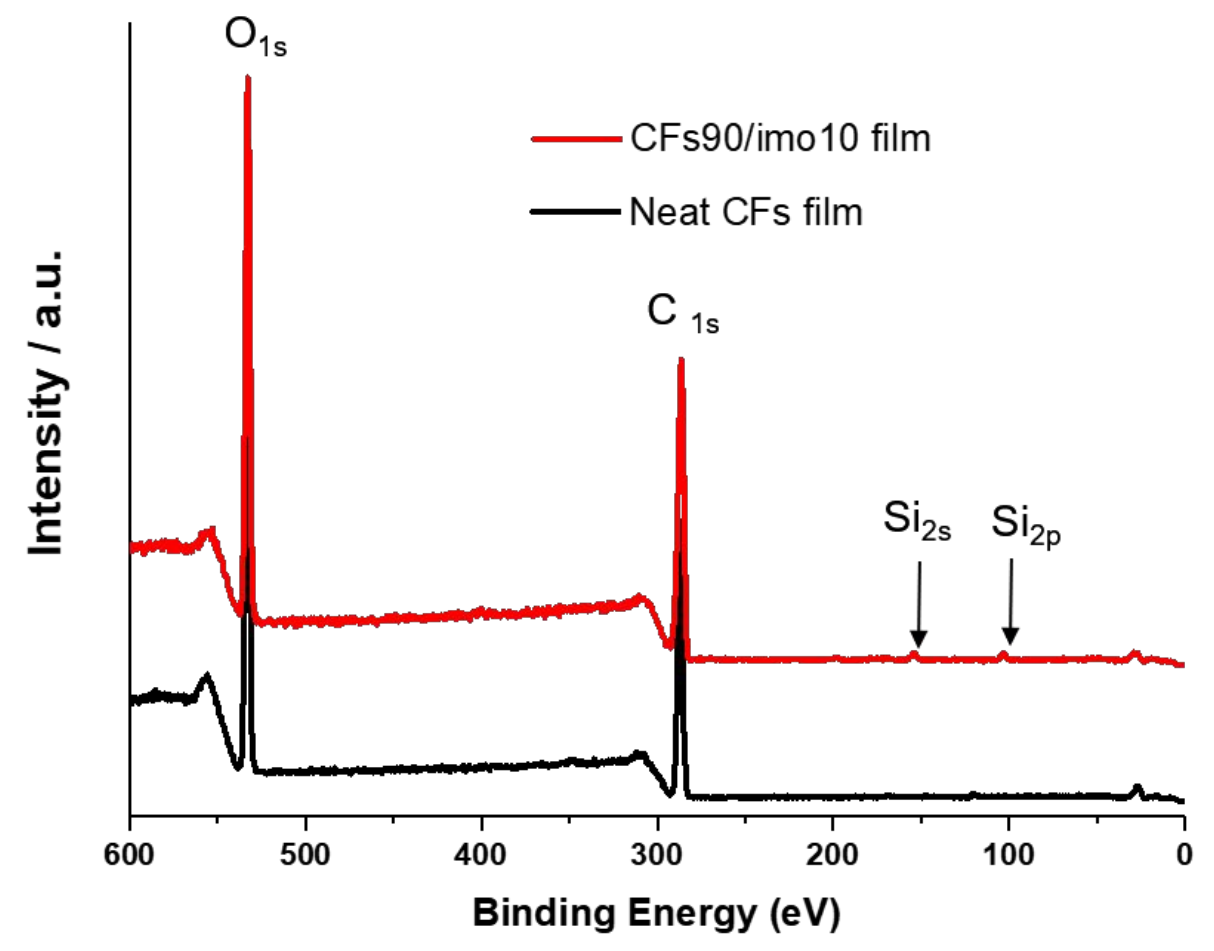

Figure S6 Wide-scan XPS of neat CFs and CFs90/Imo10 hybrid film.

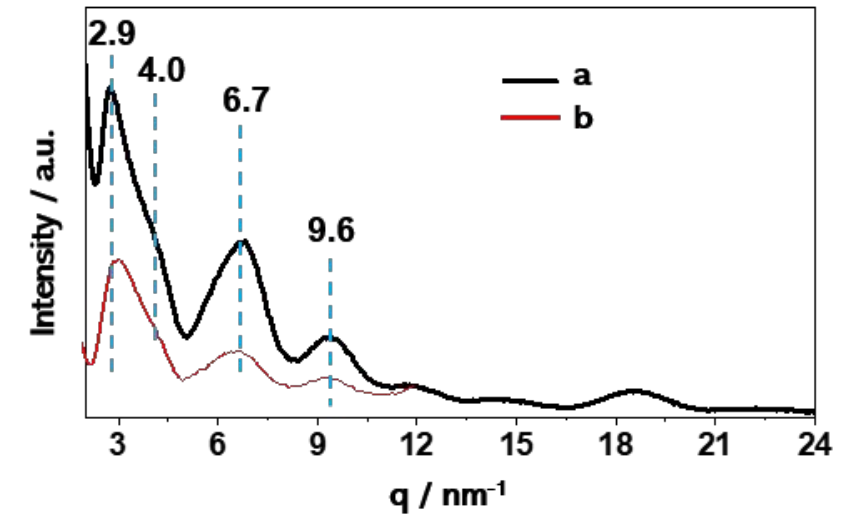

Figure S7 WAXD profile of (a) neat imogolite and (b) the one obtained by the subtraction between neat CFs and CFs90/Imo10 hybrid film. 


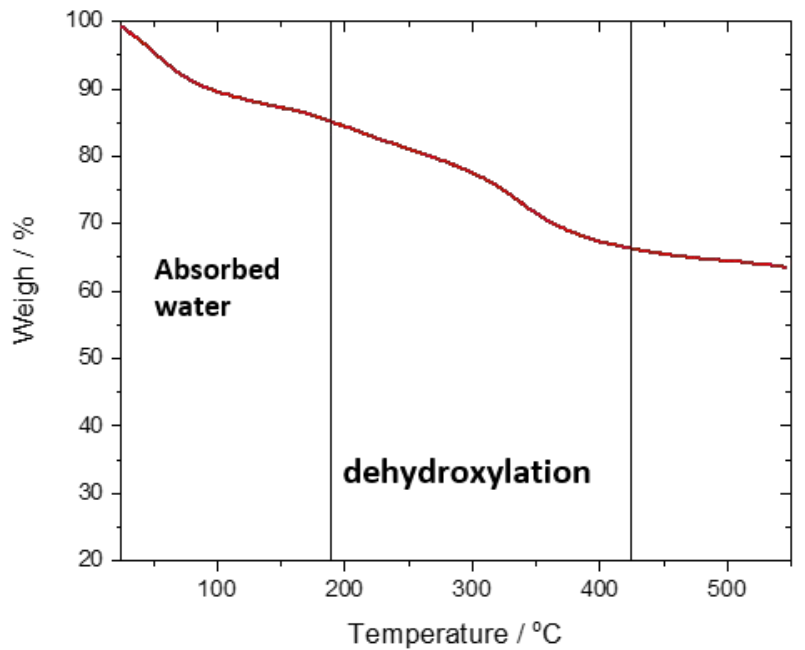

Figure S8 TGA curve of imogolite nanotubes, the temperature ramp rate was $10{ }^{\circ} \mathrm{C} \mathrm{min}^{-1}$.

Table S1 Mechanical properties of neat CFs, and CFs hybrid films with the imogolite contents of 1, 5, 10wt $\%$

\begin{tabular}{l|ccc|ccc|}
\hline & \multicolumn{3}{|c|}{ RH 5\% } & \multicolumn{3}{c|}{ RH 60\% } \\
\cline { 2 - 5 } & $\begin{array}{c}\text { Young's } \\
\text { Modulus / } \\
\text { GPa }\end{array}$ & $\begin{array}{c}\text { Elongation } \\
/ \%\end{array}$ & $\begin{array}{c}\text { Strength } \\
/ \mathrm{MPa}\end{array}$ & $\begin{array}{c}\text { Young's } \\
\text { Modulus } / \\
\mathrm{GPa}\end{array}$ & $\begin{array}{c}\text { Elongation } \\
/ \%\end{array}$ & $\begin{array}{c}\text { Strength } \\
/ \mathrm{MPa}\end{array}$ \\
\hline Neat CFs & $4.0 \pm 0.5$ & $5.6 \pm 1.7$ & $165 \pm 8$ & $3.2 \pm 1.0$ & $16.0 \pm 1.7$ & $115 \pm 10$ \\
\hline CFs99/Imo1 & $3.9 \pm 0.8$ & $6.8 \pm 1.4$ & $169 \pm 5$ & $3.1 \pm 0.3$ & $18.2 \pm 1.1$ & $117 \pm 7$ \\
\hline CFs95/Imo5 & $4.5 \pm 1.2$ & $7.9 \pm 0.9$ & $193 \pm 5$ & $3.4 \pm 0.4$ & $14.9 \pm 0.8$ & $121 \pm 5$ \\
\hline CFs90/Imo10 & $5.0 \pm 0.7$ & $5.5 \pm 0.5$ & $190 \pm 3$ & $4.0 \pm 1.1$ & $12.6 \pm 0.7$ & $137 \pm 8$ \\
\hline
\end{tabular}

